\title{
THE PRESENCE OF COLLABORATION SKILL IN ELT CLASS
}

\author{
Mutohhar \\ English Education Department of UniversitasMuria Kudus, Indonesia \\ Hakim Sudinpreeda \\ English Department, Didyasarin International College, \\ Hatyai University, Thailand \\ Agung Dwi Nurcahyo, and Fajar Kartika \\ English Education Department of UniversitasMuria Kudus, Indonesia
}

\begin{abstract}
One of the skills that must be possessed in the 21st century is collaboration skill. It requires teachers to present orprovide it in the learning process, so that later students are expected to be able to implement it in their real life. The study reported in this paper aims to describe the implementation of collaboration skill in the process of teaching and learning. The data collected by means of close-ended questionnaires and guided interview that were administered to 125 freshman students of the English Education Department of Universitas Muria Kudus. The result shows that $84 \%$ of the students said that the teacher has implemented the collaboration skill, however from $84 \%$, only $48 \%$ is categorized as instructionally effective. It is suggested that the teachers should manage some instructions and control how the instructions are executed.
\end{abstract}

Key words: $21^{\text {st }}$ centuryskills, collaboration skill, effective instruction.

\section{INRODUCTION}

The 21 st century has brought many changes in all lines of human life (Miller; 2001). To be part of the 21st century, one must master four skills, namely, communication, collaboration, creativity and critical thinking regarded as the $21^{\text {st }}$ century skills. These skills are demanded to foster their competitiveness in the challenging global era(Turiman et al., 2012).Amongthe four skills above, collaboration is one of the tough challenges, especially in the workplace besides communication, ICT literacy and social and cultural competencies(Dede, 2010). Some people have not been successful in workplace because they are not able to collaborate with others. Today is the era of ICT in which almost all activities are facilitated by ICT. However, there is still human social aspect which cannot be separated from the human life; it is collaboration (So \& Brush, 2008).

Higher education has a very vital role in building human resources. Higher education can also be called the last gate for someone before entering workforce. Unfortunately, the study conducted by Trilling and Fadel (2009) shows that high school graduates, diplomas and higher education are still less competent in terms 
of collaboration(Winiasri et al., 2020). The 21st century, which is characterized by the use of information and communication technology, has changed the way we learn and work, the nature of work that can be done, and the meaning of social relations.It shows another reason why maintaining the ability of collaboration is highly needed in today's century in the frame of reserving human potentials as social entity in digital era.Joint decision making, sharing information, collaborating, innovating, and working speed are very important aspects at this time(Haruthaitlianasan, 2020). As a consequence, higher education is challenged to find ways to enable students to succeed in work and life through mastering skills including collaboration skill, as well as being able to think creatively and innovatively.

In a learning process, there are many possibilities for teachers to develop collaboration skill through collaborative learning experiences created in accordance with learning objectives both in online or offline learning activity (Rapchak, 2018), for example: a teacher provides authentic project-based activities to students to be conducted collaboratively together in groups. There have actually been various collaborative learning techniques that can be used by teachers, such as role play, jigsaw, think pair share, roundtable and many other cooperative learning techniques. As suggested by Dillenbourg (1999), Collaborative Learning (CL) can be implemented in many different forms (Garris et al., 2018). Teachers have been provided by various models of CL in form of either online or offline activity, so they need to adjust it with the classroom situation and student's characteristics.

Collaborative Learning can be well implemented depending on how teachers manage their classroom so as to create effective instructions. Appropriate instructions really give influence towards how students go through with the learning activities. A study has proven the effect of good instructions on ESL students' learning performance in writing class (Zhang, 2013). Another research also shows the impact of good instructions to the learning performance of ESL students (Song, 2006). Appropriate instructions really help teachers in realizing their learning outcomes. Teachers should be able to provide a good instructional design to make the learning and teaching process a success, so as to develop students' collaboration skill(Craft et al., 2014). This study aims to describe how teachersimplement collaboration skill in the process of teaching and learningat the English Education Department of Universitas Muria Kudus. It also investigates to what extent teachers are able to give effective instructions during the learning activities.

\section{METHOD}

The study tries to explore a case of the implementation of collaboration skill in the teaching and learning process of English Language Teaching (ELT) at the English Education Department (EED). It also investigates how teachers manage their instructions to foster collaborative learning being seen from the student's perspective. The datawere collected byusing a close-ended questionnaire and a guided interview administered to 125 freshman students of the EED's students of Universitas Muria Kudus of the academic year of 2019-2020. The close-ended 
questionnaire was used to explore the implementation of collaboration skill through several questions, among others: (a) Has your teacher implemented a collaborative learning? (b) When did your teacher implement collaborative learning during the class? (c) What classroom activities facilitate the collaborative learning (in pre-teaching stage, whilst teaching stage and post teaching stage)? and (d) Did you find the indicators of the implementation of collaborative learning? Meanwhile, the guided interview was applied to get the supporting data to what extent the teachers could manage effective instructions during the learning activities. The questions given in the guided interview were: (1) What English skills did you learn more? (2) Could you please tell me the method used by the English teacher and the activities given by the English teacher? (3) Was the method effective? and (4) Did the classroom activities improve your skills beside English skill?

\section{FINDINGS AND DISCUSSION}

The study shows that there were $84 \%$ of the students saying that the teachers had implemented collaboration skill during the learning process. In the perspective of students, collaboration skill was believed to have been trained to students through some activities which facilitated a collaborative learning. As described by the following diagram (figure 1), the majority of students stated that their teachers had applied collaborative learning which meant that students' collaboration skill was practically trained.

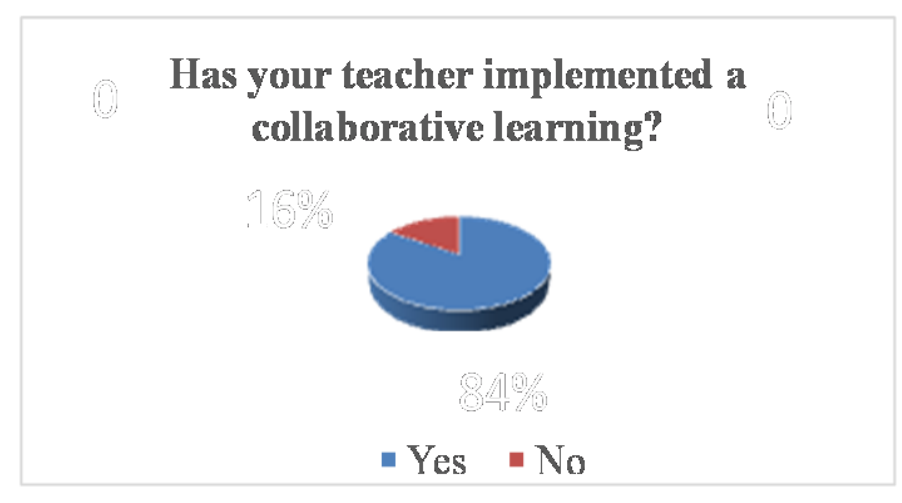

Figure 1. The Implementation of Collaborative Learning

The implementation of Collaborative Learning (CL) was found in every stage (step) of teaching, as described in figure 2. The students perceived that thecollaborative learning was mostly practiced in Whilst Teaching (75\% of students), while in Post Teaching it was considered appearing by $23 \%$ of the students, and the rest of the students ( $2 \%$ of students). 


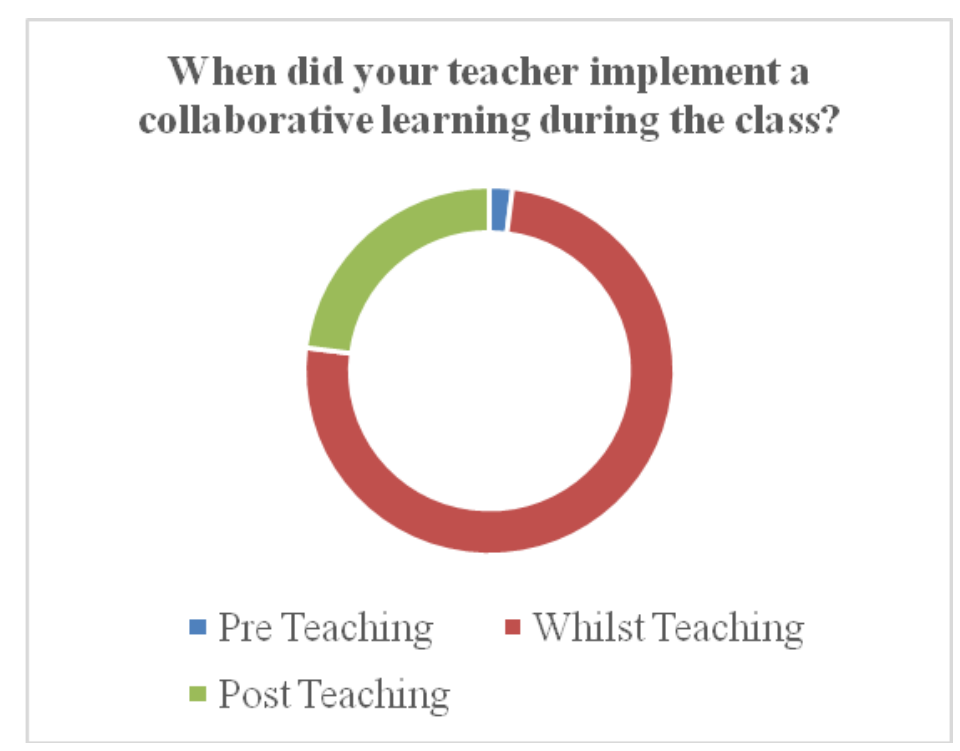

Figure 2. Steps of the Implementation of Collaborative Learning during the Class

In the beginning of the teaching and learning activity, Collaborative Learning (CL) was believed to be applied by the teachers as stated by all of the students with different Warming Up activities (figure 3), such as game and quiz. It shows that collaboration skill had been engaged in the class starting from the PreTeaching step with various activities.

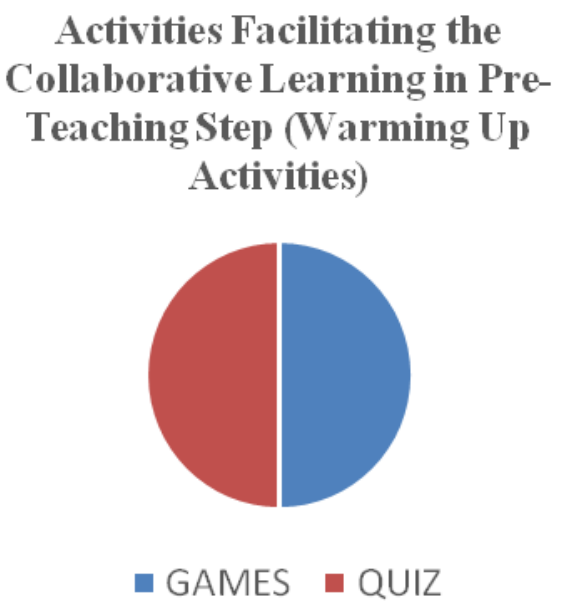

Figure 3. The Implementation of Collaborative Learning in Pre-Teaching Step

Collaborative Learning (CL) usually takes longer time than ordinary classroom activities, so it is appropriately allocated with enough duration of learning time. When teachers use this teaching method in the learning process, they need to consider engaging activities facilitating Collaborative Learning (CL) maximally in Whilst-Teaching Step of the class since this step is usually allocated with longer time compared with pre-teaching and post teaching. The study also 
found that CL appeared in Whilst-Teaching Step with various activities such reading, writing and speaking as seen in figure 4 .

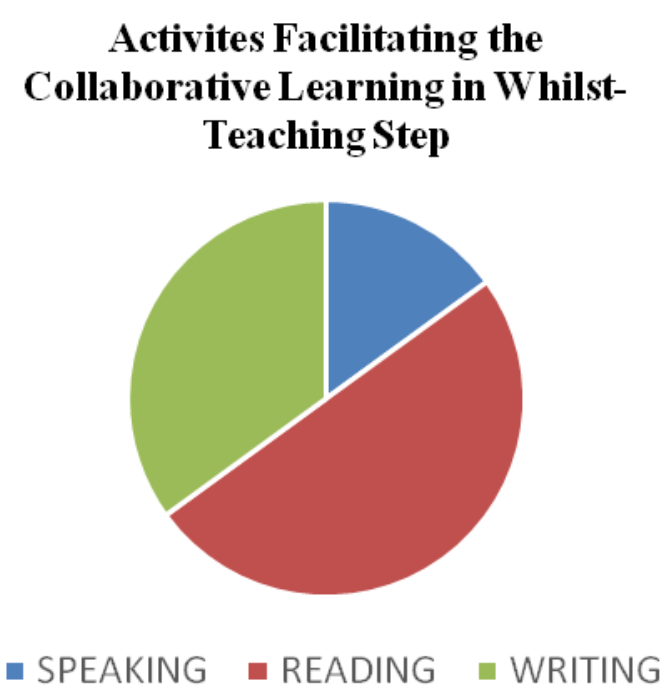

Figure 4. The Implementation of Collaborative Learning in Whilst-Teaching Step

While in Post-Teaching Step or the closing stage of class, Collaborative Learning (CL) is still possibly applied by teachers with various activities of learning material review including for the follow up of the current classroom learning activity. There are various learning activities in Post-Teaching Step which are feasible for CL to apply, such as doing exercise, group review and home work as found in the study (see figure 5). These activities are possibly conducted for engaging CL since they can be implemented individually or in group.

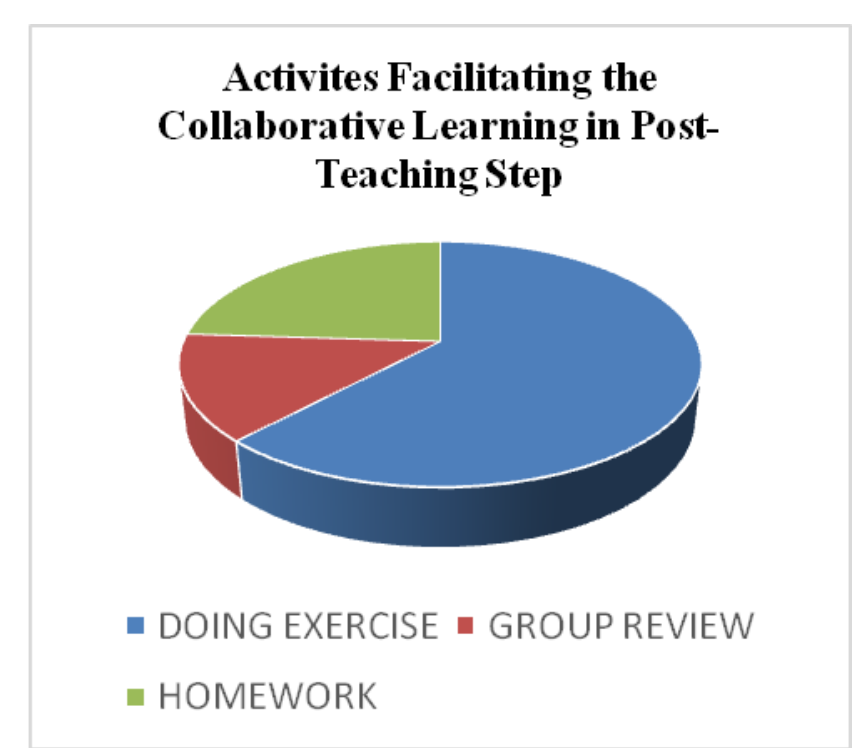

Figure 5. The Implementation of Collaborative Learning in Post-Teaching Step 
There are many learning activities which can be engaged with Collaborative Learning (CL) so far collaboration or cooperation are possibly practiced by students in group. Joint exercise has factually been effective to promote cooperation or collaboration for it practically fosters students' motivation work together with deliberation (Alshuraidah \& Storch, 2019). When being asked about indicators of the implementation of CL, the students perceived that those indicators existed in their learning activities in terms of the presence of shared experience, responsibility and cooperation. However, the indicators of CL in this case of study did not strongly appear as shown in figure 6 .

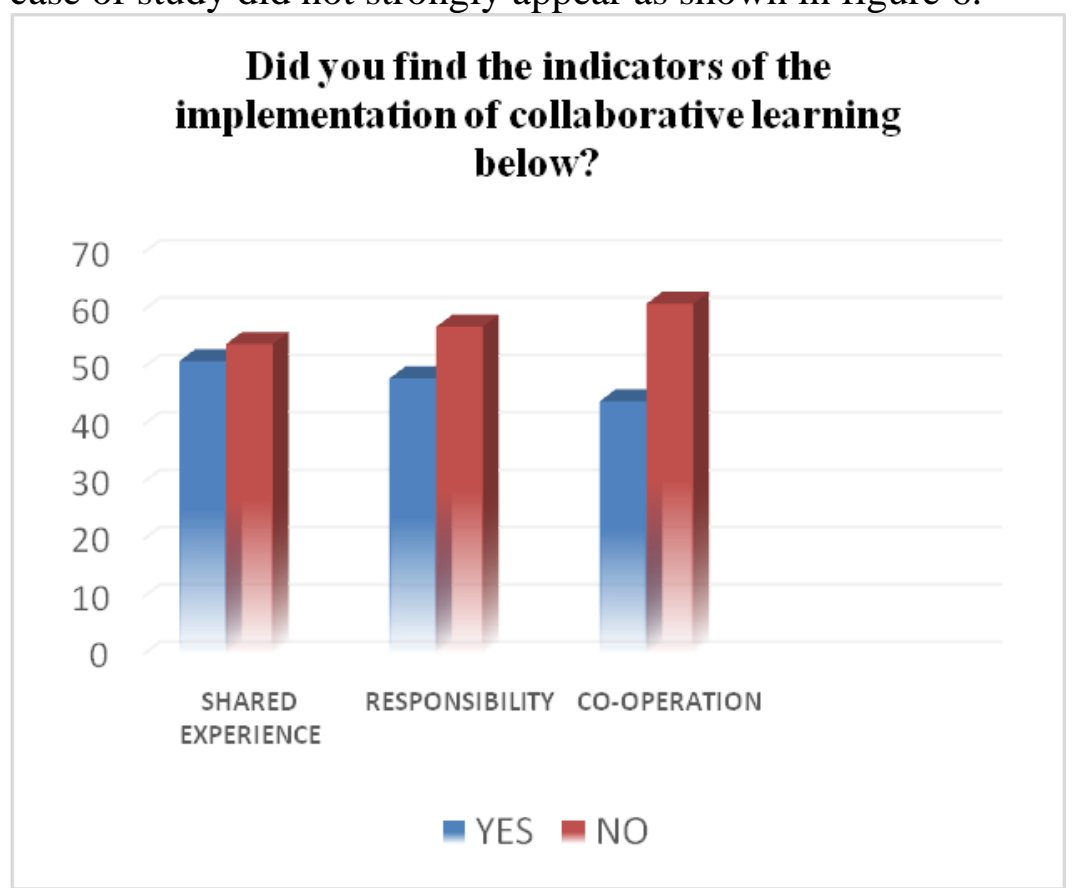

Figure 6. Indicators of the Implementation of Collaborative Learning

Based on the above diagram of indicators as well as to be connected with the result of guided interview, the study found that only $48 \%$ of the students considered the teacherswere able to managetheir instructionseffectively. The questions in the guided interview were mostly related to what methods and classroom activities applied by the teachers during the class as well as whether the methods and activities in the learning process effective or not to promote the students' collaboration skill.

\section{CONCLUSION AND SUGGESTION}

The result of this case study confirms that based on the students' perspective, most of the teachers haveapplied Collaborative Learning (CL) which practically promotes the development of students' collaboration skill in all stages of teaching, either in Pre-Teaching, Whilst Teaching and Post Teaching. The learning activities are also considered able to facilitate the application of Collaborative Learning (CL) with certain indicators, such as shared experience, responsibility and cooperation which become other skills experienced by the 
students besides English skills. However,in terms of the effectiveness of instructions, the teachers are regarded to be in necessity to develop more effective learning instructions.

It is suggested that the teachers should manage more appropriate instructions and control how the instructions are executed so as to enable the student to practice and even improve their collaboration skill. A further research may be conducted relating to this study, i.e. developing appropriate community learning approaches which are appropriate to the characteristics of the EED students of Universitas Muria Kudus.

\section{REFERENCES}

Alshuraidah, A., \& Storch, N. (2019). Investigating a collaborative approach to peer feedback. ELT Journal, 73(2), 166-174. https://doi.org/10.1093/elt/ccy057

Craft, C., Feldon, D. F., \& Brown, E. A. (2014). Instructional design affects the efficacy of simulation-based training in central venous catheterization. American Journal of Surgery, 207(5), 782-789. https://doi.org/10.1016/j.amjsurg.2013.06.003

Dede, C. (2010). Technological supports for acquiring twenty-first-century skills. International Encyclopedia of Education, 158-166. https://doi.org/10.1016/B978-0-08-044894-7.00739-9

Garris, W. R., Lester, L., Doran, E., Lowery, A., \& Weber, A. (2018). iCollaborate or not: Does technology impede collaborative learning among primary grade students? International Journal of Learning, Teaching and Educational Research, 17(5), 64-81. https://doi.org/10.26803/ijlter.17.5.5

Haruthaitlianasan, T. (2020). Effects of school policies toward competitive and collaborative approaches on teachers' instruction and students' learning in schools in southern Thailand. Kasetsart Journal of Social Sciences, 41(2), 262-268. https://doi.org/10.1016/j.kjss.2018.07.022

Rapchak, M. E. (2018). Collaborative Learning in an Information Literacy Course: The Impact of Online Versus Face-to-face Instruction on Social Metacognitive Awareness. Journal of Academic Librarianship, 44(3), 383390. https://doi.org/10.1016/j.acalib.2018.03.003

So, H. J., \& Brush, T. A. (2008). Student perceptions of collaborative learning, social presence and satisfaction in a blended learning environment: Relationships and critical factors. Computers and Education, 51(1), 318-336. https://doi.org/10.1016/j.compedu.2007.05.009

Song, B. (2006). Content-based ESL instruction: Long-term effects and outcomes. English for Specific Purposes, 25(4), 420-437. https://doi.org/10.1016/j.esp.2005.09.002 
Turiman, P., Omar, J., Daud, A. M., \& Osman, K. (2012). Fostering the 21st Century Skills through Scientific Literacy and Science Process Skills.

Procedia - Social and Behavioral Sciences, 59, 110-116.

https://doi.org/10.1016/j.sbspro.2012.09.253

Winiasri, L., Nurlaela, L., \& Sumbawati, M. S. (2020). Vocational Campus Readiness In The Disruption Era : A Case Study In Aviation Polytechnic of Surabaya. 2(6), 407-411.

https://doi.org/https://doi.org/10.29103/ijevs.v2i6.2570

Zhang, C. (2013). Effect of instruction on ESL students' synthesis writing. Journal of Second Language Writing, 22(1), 51-67. https://doi.org/10.1016/j.jslw.2012.12.001 